NBER WORKING PAPER SERIES

\title{
LIQUIDITY TRAPS AND EXPECTATION DYNAMICS: FISCAL STIMULUS OR FISCAL AUSTERITY?
}

\author{
Jess Benhabib \\ George W. Evans \\ Seppo Honkapohja \\ Working Paper 18114 \\ http://www.nber.org/papers/w18114 \\ NATIONAL BUREAU OF ECONOMIC RESEARCH \\ 1050 Massachusetts Avenue \\ Cambridge, MA 02138 \\ May 2012
}

Financial support from National Science Foundation Grant no. SES-1025011 is gratefully acknowledged. Any views expressed are those of the authors and do not necessarily reflect the views of the Bank of Finland or the National Bureau of Economic Research.

NBER working papers are circulated for discussion and comment purposes. They have not been peerreviewed or been subject to the review by the NBER Board of Directors that accompanies official NBER publications.

(C) 2012 by Jess Benhabib, George W. Evans, and Seppo Honkapohja. All rights reserved. Short sections of text, not to exceed two paragraphs, may be quoted without explicit permission provided that full credit, including $\odot$ notice, is given to the source. 
Liquidity Traps and Expectation Dynamics: Fiscal Stimulus or Fiscal Austerity?

Jess Benhabib, George W. Evans, and Seppo Honkapohja

NBER Working Paper No. 18114

May 2012

JEL No. E52,E58,E63

\begin{abstract}
$\underline{\text { ABSTRACT }}$
We examine global dynamics under infinite-horizon learning in New Keynesian models where the interest-rate rule is subject to the zero lower bound. As in Evans, Guse and Honkapohja (2008), the intended steady state is locally but not globally stable. Unstable deflationary paths emerge after large pessimistic shocks to expectations. For large expectation shocks that push interest rates to the zero bound, a temporary fiscal stimulus or a policy of fiscal austerity, appropriately tailored in magnitude and duration, will insulate the economy from deflation traps. However "fiscal switching rules" that automatically kick in without discretionary fine tuning can be equally effective.
\end{abstract}

Jess Benhabib

Department of Economics

New York University

19 West 4th Street, 6th Floor

New York, NY 10012

and NBER

jess.benhabib@nyu.edu

George W. Evans

Department of Economics

1285 University of Oregon

Eugene, OR 97403-1285

gevans@uoregon.edu
Seppo Honkapohja

Bank of Finland

Finland

Seppo.Honkapohja@bof.fi 


\section{Introduction}

As is now recognized, a Taylor-type interest-rate rule, when combined with the Fisher equation, necessarily leads to multiple equilibria. In addition to the intended steady state at the targeted inflation rate $\pi=\pi^{*}$, there is a low-inflation unintended steady state, which in fact is likely to be deflationary. See Figure 1, which plots the Fisher equation $R=\pi / \beta$, where $\pi$ is the inflation factor, $R$ is the nominal interest rate factor and $\beta^{-1}$ is the real interest-rate factor for discount factor $0<\beta<1$. The steady state Fisher equation arises from the usual household Euler equation for consumption, when consumption is at a steady state. The interest-rate rule $R=1+f(\pi)$ is drawn so that it cuts the Fisher inflation from below at the targeted steady state $\pi^{*}$, in accordance with the Taylor principle. The zero lower bound for the net interest rate $R-1$ then implies the unintended steady state at $\pi_{L}$, provided that the interest rate rule is continuous. In fact, as shown by Benhabib, Schmitt-Grohe, and Uribe (2001), there is a continuum of perfect foresight paths, starting from an initial $\pi<\pi^{*}$, which converge asymptotically to $\pi_{L}$. The multiple equilibria issue was emphasized in Benhabib, Schmitt-Grohe, and Uribe (2001) and Benhabib, Schmitt-Grohe, and Uribe (2002), using perfect foresight analysis, and was studied under adaptive learning in Evans and Honkapohja (2005), Evans, Guse, and Honkapohja (2008) and Evans and Honkapohja (2010).

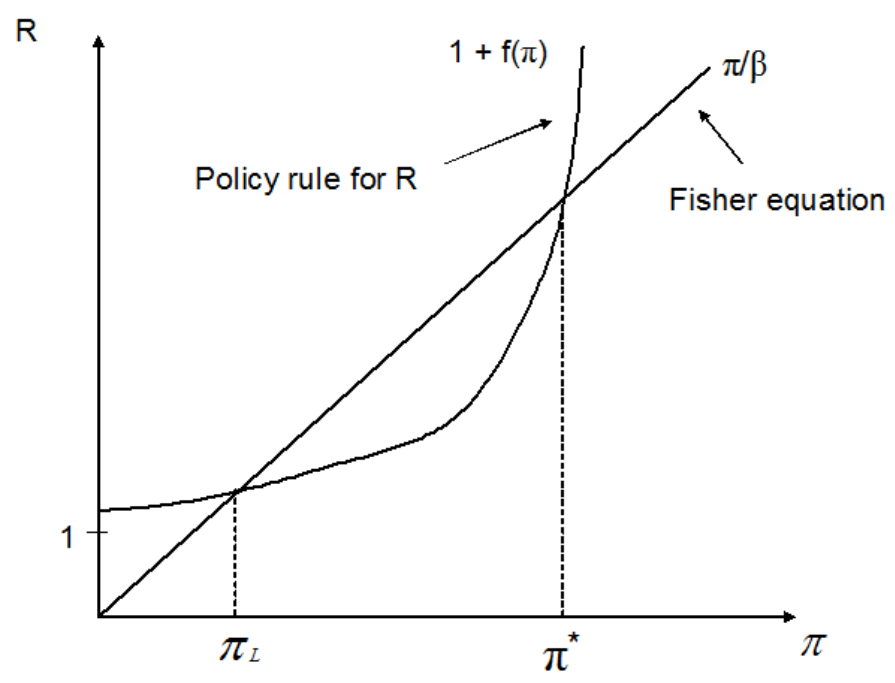

Figure 1: Multiple steady states under normal policy. 
The practical importance of the zero lower bound (ZLB) has become evident in the US and Europe since the 2007-9 financial crisis, as well as in the US during 2001-3 and in Japan since the mid 1990s. ${ }^{1}$ Recently Bullard (2010) has stressed the risk of extended periods of deflation. These events have led to extensive policy debates on the effectiveness of both fiscal policy and quantitative easing when the economy is at the ZLB.

In principle the multiplicity problem can be eliminated by suitable monetary or fiscal policies that ensures that inflation never falls below some value $\underline{\pi}>\pi_{L}$. For example, Benhabib, Schmitt-Grohe, and Uribe (2002) argue that commitment to an aggressive fiscal rule at low inflation rates would eliminate multiple equilibria via the transversality condition and ensure that under perfect foresight the economy will necessarily be at the $\pi^{*}$ steady state. They argue that in some cases a commitment to sufficient monetary expansion at low inflation can also be effective. Similarly, Evans and Honkapohja (2005) argue that in a flexible price economy a switch to a money growth rule, if inflation threatens to fall below a threshold $\underline{\pi}>\pi_{L}$, will ensure convergence to $\pi^{*}$ under learning. ${ }^{2}$ Under perfect foresight this mechanism depends on policy credibility and wealth effects to eliminate all equilibria except the $\pi^{*}$ steady state. There are however two problems with this approach: (i) it relies too heavily on perfect foresight, and (ii) the mechanism is "too powerful": bad outcomes never happen.

In this paper we explore policies designed to avoid and escape the ZLB in New Keynesian (NK) models with agents who form expectations using adaptive learning rules. We focus on NK models because, from the policy viewpoint the problem with deflation has been associated with declining output, high unemployment and/or stagnation. As we will see, these outcomes can arise under learning if pessimistic expectations lead the economy into the "deflation trap."

Under the learning approach a deflation trap is possible. This can most easily be seen using the one-step ahead Euler-equation (EE) learning approach, but is also seen under infinite-horizon (IH) learning. Can wealth effects, like the traditional Pigou effect, ensure an eventual return to the steady state? Under EE learning there is no role for wealth effects, so we

\footnotetext{
${ }^{1}$ The Japanese experience sparked renewed interest in the liquidity trap, see Krugman (1998), Eggertsson and Woodford (2003), and Svensson (2003).

${ }^{2} \mathrm{~A}$ discontinuous non-monotonic interest-rate rule, switching to $R>\pi / \beta$ for $\pi \leq$ $\pi_{L}$ would also eliminate the multiplicity. However, under learning this rule introduces instabilities.
} 
consider IH learning. In Evans and Honkapohja (2010) we still see deflation traps under IH learning. The transversality condition (TVC) fails to rule out deflationary spirals (lower and lower deflation rates) because the perceived TVC is always met along these disequilibrium paths. What about the direct wealth effects of real money and bonds? In Evans and Honkapohja (2010) these effects also fail because households are assumed Ricardian. Thus bonds and money are not perceived as net wealth. This raises the question of whether wealth effects would be effective in avoiding deflation traps if households do not have Ricardian consumption functions. We investigate this issue in detail and find that wealth effects can eventually return the economy to the $\pi^{*}$ steady state, but these mechanisms can be slow and in some cases this effect fails. ${ }^{3}$

If wealth effects or lower bounds on inflation are not sufficient to avoid the deflation trap then fiscal policy may be necessary. We therefore focus on fiscal policies. We first consider policies that implement a temporary fiscal stimulus or its converse, a policy of temporary fiscal austerity, under the assumption that future taxes adjust to keep the government solvent in the long-run. Under such policies government spending is increased or decreased for a fixed span of time. If designed carefully, these policies can yield convergence of the economy to the intended steady state, and avoid getting stuck in the liquidity trap. We show that a fiscal stimulus can be effective, i.e. deliver convergence, if its magnitude is sufficient and its duration is sufficiently short. Interestingly, a policy of fiscal austerity, i.e. a temporary cut in government spending, can also be effective. This however requires the fiscal austerity period to be sufficiently long, and the degree of initial pessimism in expectations to be relatively mild. One disadvantage of fiscal stimulus and fiscal austerity policies is that both their magnitude and duration have to be tailored to the initial expectations, so they require swift and precise discretionary action.

Therefore we turn to a second more automatic fiscal policy, a "switching fiscal rule," that ensures a return to the intended steady state $\pi^{*}$. This policy also eliminates the unintended steady state and ensures that the economy does not get stuck in a regime of deflation and stagnation. An advantage of this rule is that it is triggered automatically and does not require discre-

\footnotetext{
${ }^{3}$ Another mechanism that can prevent a deflationary spiral is a lower bound $\underline{\pi}$ on inflation due to asymmetric costs of price adjustment. However, it still can lead to falling output, to stagnation, or to a very slow return to the $\pi^{*}$ steady state. See Appendix.
} 
tionary fiscal fine tuning.

\section{The Model}

We start with the same economic framework as in Evans, Guse, and Honkapohja (2008). There is a continuum of household-firms, which produce a differentiated consumption good under monopolistic competition and priceadjustment costs. There is also a government which uses both monetary and fiscal policy and can issue public debt as described below.

The objective for agent $s$ is to maximize expected, discounted utility subject to a standard flow budget constraint:

$$
\begin{gathered}
\operatorname{Max} E_{0} \sum_{t=0}^{\infty} \beta^{t} U_{t, s}\left(c_{t, s}, \frac{M_{t-1, s}}{P_{t}}, h_{t, s}, \frac{P_{t, s}}{P_{t-1, s}}-1\right) \\
\text { st. } c_{t, s}+m_{t, s}+b_{t, s}+\Upsilon_{t, s}=m_{t-1, s} \pi_{t}^{-1}+R_{t-1} \pi_{t}^{-1} b_{t-1, s}+\frac{P_{t, s}}{P_{t}} y_{t, s},
\end{gathered}
$$

where $c_{t, s}$ is the Dixit-Stiglitz consumption aggregator, $M_{t, s}$ and $m_{t, s}$ denote nominal and real money balances, $h_{t, s}$ is the labor input into production, $b_{t, s}$ denotes the real quantity of risk-free one-period nominal bonds held by the agent at the end of period $t, \Upsilon_{t, s}$ is the lump-sum tax collected by the government, $R_{t-1}$ is the nominal interest rate factor between periods $t-1$ and $t, P_{t, s}$ is the price of consumption good $s, y_{t, s}$ is output of good $s, P_{t}$ is the aggregate price level, and the inflation rate is $\pi_{t}=P_{t} / P_{t-1}$. The subjective discount factor is denoted by $\beta$. The utility function has the parametric form

$$
U_{t, s}=\frac{c_{t, s}^{1-\sigma_{1}}}{1-\sigma_{1}}+\frac{\chi}{1-\sigma_{2}}\left(\frac{M_{t-1, s}}{P_{t}}\right)^{1-\sigma_{2}}-\frac{h_{t, s}^{1+\varepsilon}}{1+\varepsilon}-\frac{\gamma}{2}\left(\frac{P_{t, s}}{P_{t-1, s}}-1\right)^{2},
$$

where $\sigma_{1}, \sigma_{2}, \varepsilon, \gamma>0$. The final term parameterizes the cost of adjusting prices in the spirit of Rotemberg (1982). ${ }^{4}$ The household decision problem is also subject to the usual "no Ponzi game" condition.

Production function for good $s$ is given by

$$
y_{t, s}=h_{t, s}^{\alpha}
$$

\footnotetext{
${ }^{4}$ We use the Rotemberg formulation in preference to the Calvo model of price stickiness because it enables us to study global dynamics in the nonlinear system. The linearizations at the targeted steady state are identical for the two approaches.
} 
where $0<\alpha<1$. Output is differentiated and firms operate under monopolistic competition. Each firm faces a downward-sloping demand curve given by

$$
P_{t, s}=\left(\frac{y_{t, s}}{Y_{t}}\right)^{-1 / \nu} P_{t} .
$$

Here $P_{t, s}$ is the profit maximizing price set by firm $s$ consistent with its production $y_{t, s}$. The parameter $\nu$ is the elasticity of substitution between two goods and is assumed to be greater than one. $Y_{t}$ is aggregate output, which is exogenous to the firm.

The government's flow budget constraint is

$$
b_{t}+m_{t}+\Upsilon_{t}=g_{t}+m_{t-1} \pi_{t}^{-1}+R_{t-1} \pi_{t}^{-1} b_{t-1},
$$

where $g_{t}$ denotes government consumption of the aggregate good, $b_{t}$ is the real quantity of government debt, and $\Upsilon_{t}$ is the real lump-sum tax collected. We assume that fiscal policy follows a linear tax rule for lump-sum taxes as in Leeper (1991)

$$
\Upsilon_{t}=\kappa_{0}+\kappa b_{t-1}
$$

where we will usually assume that $\beta^{-1}-1<\kappa<1$. This restriction on $\kappa$ means that fiscal policy is "passive" in the terminology of Leeper (1991) and implies that an increase in real government debt leads to an increase in taxes sufficient to cover the increased interest and at least some fraction of the increased principal.

Initially we assume that $g_{t}$ is constant and given by

$$
g_{t}=\bar{g}
$$

From market clearing we have

$$
c_{t}+g_{t}=y_{t}
$$

Monetary policy is assumed to follow a global interest rate rule

$$
R_{t}-1=f\left(\pi_{t+1}^{e}, y_{t+1}^{e}\right)
$$

The function $f(\pi, y)$ is taken to be positive and non-decreasing in each argument. The rule (8) is a nonlinear forward-looking Taylor rule, where the nominal rate is set by the central bank as a function of expected inflation 
and expected output. ${ }^{5}$ We assume the existence of $\pi^{*}, R^{*}$ and $y^{*}$ such that $R^{*}=\beta^{-1} \pi^{*}$ and $f\left(\pi^{*}, y^{*}\right)=R^{*}-1$. Here $\pi^{*}$ can be viewed as the inflation target of the Central Bank, and $y^{*}$ is the natural rate of output, i.e. the level of output compatible with steady state inflation $\pi^{*}$. We assume that $\pi^{*} \geq 1$. In the numerical analysis we will use the functional form

$$
f(\pi, y)=\left(R^{*}-1\right)\left(\frac{\pi}{\pi^{*}}\right)^{A R^{*} /\left(R^{*}-1\right)}\left(\frac{y}{y^{*}}\right)^{\phi_{y}},
$$

which implies the existence steady state at $\left(\pi^{*}, y^{*}\right)$. Using $R^{*}=\pi^{*} \beta^{-1}$, we obtain $f_{\pi^{*}}\left(\pi^{*}, y^{*}\right)=A R^{*} / \pi^{*}=A \beta^{-1}$. We assume that $A>1$. Equations (6), (5) and (8) constitute "normal policy".

\subsection{Optimal decisions for private sector}

As in Evans, Guse, and Honkapohja (2008), the first-order conditions for an optimum yield

$$
\begin{gathered}
0=-h_{t, s}^{\varepsilon}+\frac{\alpha \gamma}{\nu}\left(\pi_{t, s}-1\right) \pi_{t, s} \frac{1}{h_{t, s}} \\
+\alpha\left(1-\frac{1}{\nu}\right) Y_{t}^{1 / \nu} \frac{y_{t, s}^{(1-1 / \nu)}}{h_{t, s}} c_{t, s}^{-\sigma_{1}}-\frac{\alpha \gamma \beta}{\nu} \frac{1}{h_{t, s}} E_{t, s}\left(\pi_{t+1, s}-1\right) \pi_{t+1, s} . \\
c_{t, s}^{-\sigma_{1}}=\beta R_{t} E_{t, s}\left(\pi_{t+1}^{-1} c_{t+1, s}^{-\sigma_{1}}\right)
\end{gathered}
$$

and

$$
m_{t, s}=(\chi \beta)^{1 / \sigma_{2}}\left(\frac{\left(1-R_{t}^{-1}\right) c_{t, s}^{-\sigma_{1}}}{E_{t, s} \pi_{t+1}^{\sigma_{2}-1}}\right)^{-1 / \sigma_{2}},
$$

where $\pi_{t+1, s}=P_{t+1, s} / P_{t, s}$. We now make use of the representative agent assumption. In the representative-agent economy all agents $s$ have the same utility functions, initial money and debt holdings, and prices. We assume also that they make the same forecasts $E_{t, s} c_{t+1, s} E_{t, s} \pi_{t+1, s}, E_{t, s} \pi_{t+1}$, as well as forecasts of other variables that will become relevant below. Under these assumptions all agents make the same decisions at each point in time, so that $h_{t, s}=h_{t}, y_{t, s}=y_{t}, c_{t, s}=c_{t}$ and $\pi_{t, s}=\pi_{t}$, and all agents make the same

\footnotetext{
${ }^{5}$ The main results below would also hold in the case of a contemporaneous-data Taylor rule, which is used in Evans, Guse, and Honkapohja (2008).
} 
forecasts. Imposing the equilibrium condition $Y_{t}=y_{t}=h_{t}^{\alpha}$, one obtains the equations

$$
\begin{gathered}
\frac{\alpha \gamma}{\nu}\left(\pi_{t}-1\right) \pi_{t}=h_{t}\left(h_{t}^{\varepsilon}-\alpha\left(1-\frac{1}{\nu}\right) h_{t}^{\alpha-1} c_{t}^{-\sigma_{1}}\right)+\beta \frac{\alpha \gamma}{\nu} E_{t}\left[\left(\pi_{t+1}-1\right) \pi_{t+1}\right] \\
c_{t}^{-\sigma_{1}}=\beta R_{t} E_{t}\left(\pi_{t+1}^{-1} c_{t+1}^{-\sigma_{1}}\right) \\
m_{t}=(\chi \beta)^{1 / \sigma_{2}}\left(\frac{\left(1-R_{t}^{-1}\right) c_{t}^{-\sigma_{1}}}{E_{t} \pi_{t+1}^{\sigma_{2}-1}}\right)^{-1 / \sigma_{2}}
\end{gathered}
$$

For convenience we make the assumptions $\sigma_{1}=\sigma_{2}=1$, i.e. utility of consumption and of money is logarithmic. It is also assumed that agents have point expectations, so that their decisions depend only on the mean of their subjective forecasts. This allows us to write the system as

$$
\begin{gathered}
m_{t}=\chi \beta\left(1-R_{t}^{-1}\right)^{-1} c_{t}, \\
c_{t}^{-1}=\beta r_{t+1}^{e}\left(c_{t+1}^{e}\right)^{-1}, \text { where } r_{t+1}^{e}=R_{t} / \pi_{t+1}^{e}, \text { and } \\
\frac{\alpha \gamma}{\nu}\left(\pi_{t}-1\right) \pi_{t}=h_{t}\left(h_{t}^{\varepsilon}-\alpha\left(1-\frac{1}{\nu}\right) h_{t}^{\alpha-1} c_{t}^{-1}\right)+\beta \frac{\alpha \gamma}{\nu}\left[\left(\pi_{t+1}^{e}-1\right) \pi_{t+1}^{e}\right] .
\end{gathered}
$$

Equation (13) is the nonlinear New Keynesian Phillips curve that describes the optimal price-setting by firms. The term $\left(\pi_{t}-1\right) \pi_{t}$ arises from the quadratic form of the adjustment costs, and this expression is increasing in $\pi_{t}$ over the allowable range $\pi_{t} \geq 1 / 2$. To interpret this equation, note that the bracketed expression in the first term on the right-hand side is the difference between the marginal disutility of labor and the product of the marginal revenue from an extra unit of labor with the marginal utility of consumption. The terms involving current and future inflation arise from the price-adjustment costs resulting from marginal variations in labor supply. Equation (12) is the standard Euler equation giving the intertemporal first-order condition for the consumption path. Equation (11) is the money demand function resulting from the presence of real balances in the utility function. Note that for our parameterization, the demand for real balances becomes infinite as $R_{t} \rightarrow 1$.

We now proceed to rewrite the decision rules for $c_{t}$ and $\pi_{t}$ so that they depend on forecasts of key variables over the infinite horizon. The IH learning approach in New Keynesian models was first emphasized by Preston (2005) and Preston (2006), and was used in Evans and Honkapohja (2010) to study the properties of a liquidity trap. 


\subsection{The infinite-horizon Phillips curve}

We start with an infinite-horizon version of the Phillips curve (13). Let

$$
Q_{t}=\left(\pi_{t}-1\right) \pi_{t}
$$

The appropriate root for given $Q$ is $\pi \geq \frac{1}{2}$ and so we need to impose $Q \geq$ $-\frac{1}{4}$ to have a meaningful model. Making use of the aggregate relationships $h_{t}=y_{t}^{1 / \alpha}$ and $c_{t}=y_{t}-g_{t}$ we can rewrite (13) as

$$
Q_{t}=\frac{\nu}{\alpha \gamma} y_{t}^{(1+\varepsilon) / \alpha}-\frac{\nu-1}{\gamma} y_{t}\left(y_{t}-g_{t}\right)^{-1}+\beta Q_{t+1}^{e} .
$$

Solving this forward with $g_{t}=\bar{g}$, we obtain

$$
\begin{aligned}
Q_{t}= & \frac{\nu}{\alpha \gamma} y_{t}^{(1+\varepsilon) / \alpha}-\frac{\nu-1}{\gamma} y_{t}\left(y_{t}-\bar{g}\right)^{-1}+ \\
& \frac{\nu}{\gamma} \sum_{j=1}^{\infty} \alpha^{-1} \beta^{j}\left(y_{t+j}^{e}\right)^{(1+\varepsilon) / \alpha}-\frac{\nu-1}{\gamma} \sum_{j=1}^{\infty} \beta^{j}\left(\frac{y_{t+j}^{e}}{y_{t+j}^{e}-\bar{g}}\right),
\end{aligned}
$$

where government spending is assumed to be constant over time. The expectations are formed at time $t$ and variables at time $t$ are assumed to be in the information set of the agents. We will treat (15), together with (14), as the temporary equilibrium equations that determine $\pi_{t}$, given expectations $\left\{y_{t+j}^{e}\right\}_{j=1}^{\infty}$. Later, we will consider a case where $g_{t}$ varies over time and then $y_{t+j}^{e}-\bar{g}$ becomes nety $y_{t+j}^{e}=\left(y_{t+j}-g_{t+j}\right)^{e}$ in equation (15).

In the Phillip's curve relationship (15) one might wonder why inflation does not also depend directly on the expected future aggregate inflation rate. ${ }^{6}$ Equation (10) is obtained from the first-order conditions using (3) to eliminate relative prices. Because of the representative agent assumption, each firm's output equals average output in every period. Since firms can be assumed to have learned this to be the case, we obtain (15). An alternative procedure would be to start from (10), iterate it forward and use the demand function to write the third term on the right-hand side of (10) in terms of the relative price. This would lead to a modification of (15) in which future relative prices also appear, but using the representative agent assumption and assuming that firms have learned that all firms set the same price each period, the relative price term would drop out.

\footnotetext{
${ }^{6}$ There is an indirect effect of expected inflation on current inflation via current output.
} 


\subsection{The consumption function}

To derive the consumption function from (12) we use the flow budget constraint and the NPG (no Ponzi game) to obtain an intertemporal budget constraint. First, we define the asset wealth

$$
a_{t}=b_{t}+m_{t}
$$

as the sum of holdings of real bonds and real money balances and write the flow budget constraint as

$$
a_{t}+c_{t}=y_{t}-\Upsilon_{t}+r_{t} a_{t-1}+\pi_{t}^{-1}\left(1-R_{t-1}\right) m_{t-1},
$$

where $r_{t}=R_{t-1} / \pi_{t}$. Note that we assume $\left(P_{j t} / P_{t}\right) y_{j t}=y_{t}$, i.e. the representative agent assumption is being invoked. Iterating (16) forward and imposing

$$
\lim _{j \rightarrow \infty}\left(D_{t, t+j}^{e}\right)^{-1} a_{t+j}=0
$$

where

$$
D_{t, t+j}^{e}=\prod_{i=1}^{j} r_{t+i}^{e},
$$

with $r_{t+j}^{e}=R_{t+j-1} / \pi_{t+j}^{e}$, we obtain the life-time budget constraint of the household

$$
\begin{aligned}
0 & =r_{t} a_{t-1}+\Phi_{t}+\sum_{j=1}^{\infty}\left(D_{t, t+j}^{e}\right)^{-1} \Phi_{t+j}^{e} \\
& =r_{t} a_{t-1}+\phi_{t}-c_{t}+\sum_{j=1}^{\infty}\left(D_{t, t+j}^{e}\right)^{-1}\left(\phi_{t+j}^{e}-c_{t+j}^{e}\right),
\end{aligned}
$$

where

$$
\begin{aligned}
\Phi_{t+j}^{e} & =y_{t+j}^{e}-\Upsilon_{t+j}^{e}-c_{t+j}^{e}+\left(\pi_{t+j}^{e}\right)^{-1}\left(1-R_{t+j-1}^{e}\right) m_{t+j-1}^{e} \\
\phi_{t+j}^{e} & =\Phi_{t+j}^{e}+c_{t+j}^{e}=y_{t+j}^{e}-\Upsilon_{t+j}^{e}+\left(\pi_{t+j}^{e}\right)^{-1}\left(1-R_{t+j-1}^{e}\right) m_{t+j-1}^{e}
\end{aligned}
$$

Here all expectations are formed in period $t$, which is indicated in the notation for $D_{t, t+j}^{e}$ but is omitted from the other expectational variables.

Invoking the relations

$$
c_{t+j}^{e}=c_{t} \beta^{j} D_{t, t+j}^{e}
$$


which is an implication of the consumption Euler equation (12) we obtain

$$
c_{t}(1-\beta)^{-1}=r_{t} a_{t-1}+y_{t}-\Upsilon_{t}+\pi_{t}^{-1}\left(1-R_{t-1}\right) m_{t-1}+\sum_{j=1}^{\infty}\left(D_{t, t+j}^{e}\right)^{-1} \phi_{t+j}^{e}
$$

As we have $\phi_{t+j}^{e}=y_{t+j}^{e}-\Upsilon_{t+j}^{e}+\left(\pi_{t+j}^{e}\right)^{-1}\left(1-R_{t+j-1}^{e}\right) m_{t+j-1}^{e}$, the final term in $(22)$ is

$$
\sum_{j=1}^{\infty}\left(D_{t, t+j}^{e}\right)^{-1}\left(y_{t+j}^{e}-\Upsilon_{t+j}^{e}\right)+\sum_{j=1}^{\infty}\left(D_{t, t+j}^{e}\right)^{-1}\left(\pi_{t+j}^{e}\right)^{-1}\left(1-R_{t+j-1}^{e}\right) m_{t+j-1}^{e}
$$

and using (11) we have

$$
\begin{aligned}
& \sum_{j=1}^{\infty}\left(D_{t, t+j}^{e}\right)^{-1}\left(\pi_{t+j}^{e}\right)^{-1}\left(1-R_{t+j-1}^{e}\right) m_{t+j-1}^{e} \\
= & \sum_{j=1}^{\infty}\left(D_{t, t+j}^{e}\right)^{-1}\left(\pi_{t+j}^{e}\right)^{-1}\left(-\chi \beta R_{t+j-1}^{e} c_{t+j-1}^{e}\right)=-\frac{\chi \beta}{1-\beta} c_{t} .
\end{aligned}
$$

We obtain

$$
c_{t} \frac{1+\chi \beta}{1-\beta}=r_{r} b_{t-1}+\frac{m_{t-1}}{\pi_{t}}+y_{t}-\Upsilon_{t}+\sum_{j=1}^{\infty}\left(D_{t, t+j}^{e}\right)^{-1}\left(y_{t+j}^{e}-\Upsilon_{t+j}^{e}\right) .
$$

Finally, we invoke the flow budget identity $b_{t}+m_{t}+\Upsilon_{t}-g_{t}=m_{t-1} \pi_{t}^{-1}+r_{t} b_{t-1}$, see (4), and obtain the consumption function

$$
c_{t}\left[\frac{1+\chi \beta}{1-\beta}-\chi \beta \frac{R_{t}}{R_{t}-1}\right]=b_{t}+y_{t}-g_{t}+\sum_{j=1}^{\infty}\left(D_{t, t+j}^{e}\right)^{-1}\left(z_{t+j}^{e}\right),
$$

where $z_{t+j}^{e}=y_{t+j}^{e}-\Upsilon_{t+j}^{e}$.

\section{Temporary Equilibrium and Learning}

\subsection{Equilibrium Conditions}

We now assume that agents form expectations using steady state learning, which is formulated as follows. Steady-state learning with point expectations is formalized as

$$
s_{t+j}^{e}=s_{t}^{e} \text { for all } j \geq 1 \text {, and } s_{t}^{e}=s_{t-1}^{e}+\omega_{t}\left(s_{t-1}-s_{t-1}^{e}\right)
$$


for $s=y, z$, nety, $\pi$. Here $\omega_{t}$ is called the "gain sequence," and measures the extent of adjustment of estimates to the most recent forecast error. In stochastic systems one often sets $\omega_{t}=t^{-1}$ and this "decreasing gain" learning corresponds to least-squares updating. Also widely used is the case $\omega_{t}=\omega$, for $0<\omega \leq 1$, called "constant gain" learning. In this case it is usually assumed that $\omega$ is small. ${ }^{7}$ Stability of the steady states is examined below using the simple learning rules just described.

The temporary equilibrium equations with steady state learning are:

1. The aggregate demand

$$
\begin{aligned}
y_{t} & =g_{t}+\left[\frac{1+\chi \beta}{1-\beta}-\chi \beta \frac{1+f\left(\pi_{t}^{e}\right)}{f\left(\pi_{t}^{e}\right)}\right]^{-1}\left[b_{t}+y_{t}-g_{t}+\sum_{j=1}^{\infty}\left(D_{t, t+j}^{e}\right)^{-1} z_{t}^{e}\right] \\
& =g_{t}+\left[\frac{1+\chi \beta}{1-\beta}-\chi \beta \frac{1+f\left(\pi_{t}^{e}\right)}{f\left(\pi_{t}^{e}\right)}\right]^{-1}\left[b_{t}+y_{t}-g_{t}+\frac{\pi_{t}^{e}}{1+f\left(\pi_{t}^{e}\right)-\pi_{t}^{e}} z_{t}^{e}\right] \\
& \equiv g_{t}+C\left(\pi_{t}^{e}, z_{t}^{e}, b_{t}, y_{t}\right),
\end{aligned}
$$

where it is assumed that agents know the interest rate rule.

2. The nonlinear Phillips curve

$$
\begin{aligned}
\pi_{t} & =Q^{-1}\left[\tilde{K}\left(y_{t}, y_{t+1}^{e}, y_{t+2}^{e} \ldots\right)\right] \\
& \equiv Q^{-1}\left[K\left(y_{t}, y_{t}^{e}\right)\right] \\
& \equiv G_{2}\left(y_{t}, y_{t}^{e}\right)
\end{aligned}
$$

where

$$
\begin{aligned}
Q\left(\pi_{t}\right) \equiv & \left(\pi_{t}-1\right) \pi_{t} \\
K\left(y_{t}, y_{t}^{e}\right) \equiv & \frac{\nu}{\gamma}\left(\alpha^{-1} y_{t}^{(1+\varepsilon) / \alpha}-\left(1-\nu^{-1}\right) \frac{y_{t}}{\left(y_{t}-g_{t}\right)}\right) \\
& +\frac{\nu}{\gamma}\left(\beta(1-\beta)^{-1}\left(\alpha^{-1}\left(y_{t}^{e}\right)^{(1+\varepsilon) / \alpha}-\left(1-\nu^{-1}\right) \frac{y_{t}^{e}}{n e t y_{t}^{e}}\right)\right)
\end{aligned}
$$

and where until Section 4 we assume that nety $y_{t}^{e}=y_{t}^{e}-\bar{g}$.

\footnotetext{
${ }^{7}$ For discussion and analytical results concerning adaptive learning in a wide range of macroeconomic models, see for example Sargent (1993), Evans and Honkapohja (2001), Sargent (2008), and Evans and Honkapohja (2009).
} 
3. Bond dynamics

$$
b_{t}+m_{t}=g-\Upsilon_{t}+\frac{R_{t-1}}{\pi_{t}} b_{t-1}+\frac{m_{t-1}}{\pi_{t}} .
$$

4. Money demand

$$
m_{t}=\chi \beta \frac{R_{t}}{R_{t}-1} c_{t}
$$

5. Interest rate rule

$$
R_{t}=1+f\left(\pi_{t}^{e}, y_{t}^{e}\right)
$$

The state variables are $b_{t-1}, m_{t-1}$, and $R_{t-1}$. The system in general has four expectational variables: output $y_{t}^{e}$, inflation $\pi_{t}^{e}$, income net of taxes $z_{t}^{e}$ and net output nety $y_{t}^{e}$. In cases where government spending is constant we have $n e t y_{t}^{e}=y_{t}^{e}-\bar{g}$, so that it is not necessary to introduce expectations of net output separately. The evolution of expectations is given by

$$
\begin{aligned}
y_{t}^{e} & =y_{t-1}^{e}+\omega\left(y_{t-1}-y_{t-1}^{e}\right) \\
\pi_{t}^{e} & =\pi_{t-1}^{e}+\omega\left(\pi_{t-1}-\pi_{t-1}^{e}\right) \\
z_{t}^{e} & =z_{t-1}^{e}+\omega\left(z_{t-1}-z_{t-1}^{e}\right) \\
\text { nety }_{t}^{e} & =\operatorname{nety}_{t-1}^{e}+\omega\left(\text { net } y_{t-1}-\text { nety }_{t-1}^{e}\right)
\end{aligned}
$$

We note that equation (33) is used below only in cases where the households are Non-Ricardian.

\subsection{The Case of Ricardian Consumers}

The preceding derivation of the consumption function assumes households that do not act in a Ricardian way, i.e. they do not impose the intertemporal budget constraint (IBC) of the government. For Ricardian consumers we modify the consumption function as in Evans and Honkapohja (2010). ${ }^{8}$ From (4) one has

$$
\begin{aligned}
b_{t}+m_{t}+\Upsilon_{t} & =g_{t}+m_{t-1} \pi_{t}^{-1}+r_{t} b_{t-1} \text { or } \\
b_{t} & =\Delta_{t}+r_{t} b_{t-1} \text { where } \\
\Delta_{t} & =g_{t}-\Upsilon_{t}-m_{t}+m_{t-1} \pi_{t}^{-1} .
\end{aligned}
$$

\footnotetext{
${ }^{8}$ Evans, Honkapohja, and Mitra (2012) state the assumptions under which Ricardian Equivalence holds along a path of temporary equilibria with learning if agents have an infinite decision horizon.
} 
By forward substitution, and assuming

$$
\lim _{T \rightarrow \infty} D_{t, t+T} b_{t+T}=0
$$

we get

$$
0=r_{t} b_{t-1}+\Delta_{t}+\sum_{j=1}^{\infty} D_{t, t+j}^{-1} \Delta_{t+j}
$$

Note that $\Delta_{t+j}$ is the primary government deficit in $t+j$, measured as government purchases less lump-sum taxes and less seigniorage. Under the Ricardian Equivalence assumption, we assume that agents at each time $t$ expect this constraint to be satisfied, i.e.

$$
\begin{aligned}
0 & =r_{t} b_{t-1}+\Delta_{t}+\sum_{j=1}^{\infty}\left(D_{t, t+j}^{e}\right)^{-1} \Delta_{t+j}^{e}, \text { where } \\
\Delta_{t+j}^{e} & =g_{t+j}^{e}-\Upsilon_{t+j}^{e}-m_{t+j}^{e}+m_{t+j-1}^{e}\left(\pi_{t+j}^{e}\right)^{-1} \text { for } j=1,2,3, \ldots
\end{aligned}
$$

A Ricardian consumer assumes that (35) holds. His flow budget constraint (16) can be written as:

$$
\begin{aligned}
b_{t} & =r_{t} b_{t-1}+\psi_{t}, \text { where } \\
\psi_{t} & =y_{t}-\Upsilon_{t}-m_{t}-c_{t}+\pi_{t}^{-1} m_{t-1}
\end{aligned}
$$

The relevant transversality condition is now (35). Iterating forward and using (21) together with (35) yields the consumption function

$$
c_{t}=(1-\beta)\left(y_{t}-g_{t}+\sum_{j=1}^{\infty}\left(D_{t, t+j}^{e}\right)^{-1}\left(\text { net } y_{t+j}^{e}\right)\right) \text {. }
$$

For details see Evans and Honkapohja (2010).

We now consider the case where government spending is constant $g_{t}=\bar{g}$. In this case we can assume that $n e t y_{t+j}^{e}=y_{t+j}^{e}-\bar{g}$. For simplicity, in this section we drop the dependence of the interest rate rule on expected output so that $\phi_{y}=0$ and $R_{t}=1+f\left(\pi_{t}^{e}\right)$. With steady state learning this leads to the aggregate output equation

$$
\begin{aligned}
y_{t} & =\bar{g}+\left(\beta^{-1}-1\right)\left(y_{t}^{e}-\bar{g}\right)\left(\frac{\pi_{t}^{e}}{1+f\left(\pi_{t}^{e}\right)-\pi_{t}^{e}}\right) \\
& \equiv G_{1}\left(y_{t}^{e}, \pi_{t}^{e}\right)
\end{aligned}
$$


The temporary equilibrium is now given by the Phillips curve (26), the output equation with Ricardian consumption function (38) and the independent equation for the evolution of debt and money. Note that the Ricardian system just depends on expectations of output and inflation, so that the paths of inflation and output do not depend on the evolution of bonds and real balances. The (small gain) dynamics can therefore be described by the Estability differential equation using a two-dimensional phase diagram. (See Evans and Honkapohja (2001).)

The E-stability differential equations are given by

$$
\begin{aligned}
& \frac{d y^{e}}{d \tau}=G_{1}\left(y^{e}, \pi^{e}\right)-y^{e} \\
& \frac{d \pi^{e}}{d \tau}=G_{2}\left(y^{e}, \pi^{e}\right)-\pi^{e}
\end{aligned}
$$

where using (26) we define $G_{2}\left(y^{e}, \pi^{e}\right)=G_{2}\left(G_{1}\left(y^{e}, \pi^{e}\right), y^{e}\right)$. The steady state equations for $h, c$ and $\pi$ are

$$
\begin{gathered}
c=h^{\alpha}-\bar{g} \\
-h^{1+\varepsilon}+\frac{\alpha \gamma}{\nu}(1-\beta)(\pi-1) \pi+\alpha\left(1-\frac{1}{\nu}\right) h^{\alpha} c^{-1}=0 \\
1+f(\pi)=\beta^{-1} \pi .
\end{gathered}
$$

Steady states are defined by $R=1+f(\pi)$ together with the the Fisher relationship $R=\pi \beta^{-1}$. For $A>1$ there are two steady states, $\left(y^{*}, \pi^{*}\right)$ and $\left(y_{L}, \pi_{L}\right)$ with $\pi_{L}<\pi^{*}$. Local E-stability results for the Ricardian case are given by Proposition 2 of Evans and Honkapohja (2010): the $\pi^{*}$ steady state is locally stable under learning, while for small $\gamma$, the $\pi_{L}$ steady state is locally unstable under learning, with the local learning dynamics taking the form of a saddle. ${ }^{9}$

One can also look at the global learning dynamics using a phase diagram. For typical parameter value the learning dynamics are as shown in Figure 2. The figure is constructed with the following parameter values $A=2.5$, $\pi^{*}=1.02, \beta=0.99, \alpha=0.7, \gamma=350, v=21, \varepsilon=1$, and $g=0.2$. While $A=1.5$ is the usual value for the interest rate rule, we choose $A=2.5$ to

\footnotetext{
${ }^{9}$ Instability of the low inflation steady state under learning and the divergent paths were earlier described in McCallum (2002), Eusepi (2007), and Evans, Guse, and Honkapohja (2008). Bullard and Cho (2005) show the possibility of "escape paths" toward the lowinflation outcome.
} 
clearly separate the intended and unintended steady states in the numerical analysis. Our results are robust to using $A=1.5$. The calibrations of the target inflation rate $\pi^{*}$, the discount factor $\beta$, the labor share $\alpha$, and the approximate GDP share of government spending, $g$ are standard. We set the labor supply elasticity $\varepsilon=1$. The value of $v=21$ was chosen so that the implied markup of prices over marginal cost at the steady state is 5 percent, which is consistent with the evidence presented by Basu and Fernald (1997). Following Sbordone (2002), we set $\gamma$, the parameter governing the disutility of deviating from the inflation target, at $\gamma=-17.5(1+\nu)=350$. We also assume that interest rate expectations $r_{t+j}^{e}=R_{t+j-1} / \pi_{t+j}^{e}$ revert to the steady state value $\beta^{-1}$ for $j \geq T$. In Figure 2 we use $T=28$, which under a quarterly calibration corresponds to 7 years. ${ }^{10}$

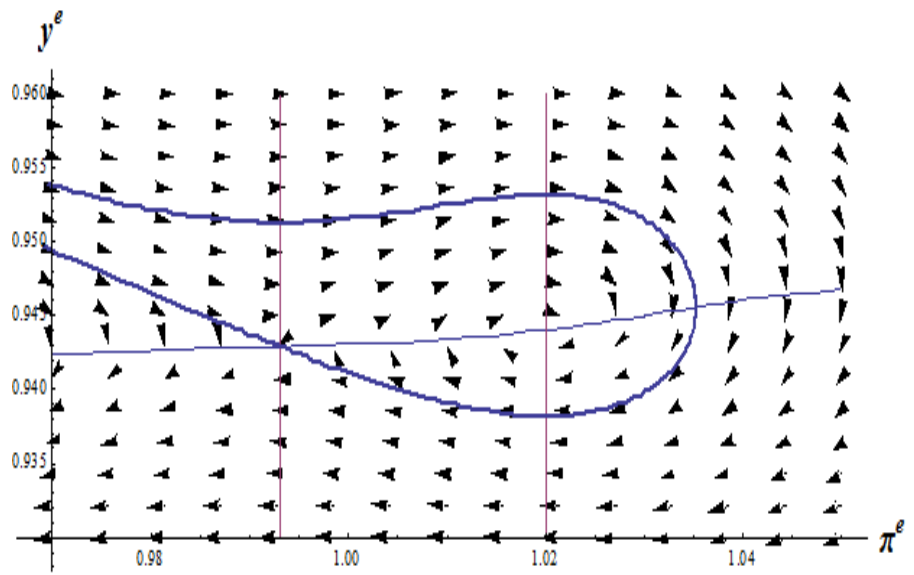

Figure 2: Global learning dynamics - the Ricardian case.

The main features that stand out are first, the local stability of the $\pi^{*}$ steady state. There is in fact a "corridor of stability" defined by a set of expectations that converge to the $\pi^{*}$ steady state. (The term "corridor" is due to Leijonhufvud (1973).) This corridor is defined by the region enclosed within the stable manifold of the unintended steady state $\left(y_{L}, \pi_{L}\right)$. Second, we see that convergence to $\pi^{*}$ is locally cyclical. Third, it can be seen that there is a heteroclinic orbit connecting the $\pi_{L}$ steady state with the $\pi^{*}$ steady state. Finally, we observe that for initial points outside the corridor of stability the trajectory of expectations is (at least eventually) led into a deflation trap in which $\left(y^{e}, \pi^{e}\right)$ fall steadily over time. Along these paths we have

\footnotetext{
${ }^{10}$ This choice is roughly in line with data on the aftermath of financial crises. See Reinhart and Rogoff (2009).
} 
falling actual output and inflation, intensifying as deflation sets in. Even though the financial wealth of agents is getting very large over time along such a deflationary path, Ricardian agents do not respond by sufficiently increasing consumption, as they expect that the increase in their wealth will be offset by future growth in taxes.

\subsection{Wealth Effects and Non-Ricardian Consumers}

We next consider Non-Ricardian consumers. A traditional argument against the liquidity trap dates back to Pigou (1943) and Patinkin (1965). In principle, wealth effects could prevent a deflation trap: if declining prices lead to higher perceived wealth, agents will increase their spending. This can be investigated numerically. Our simulations indicate that wealth effects can indeed stabilize the economy at $\pi^{*}$, although in some cases we have paths that converge to $\pi_{L}$, accompanied by exploding debt.

The dynamics under learning when consumers are not Ricardian are given in sub-section 3.1. These describe the temporary equilibrium, and the adjustment of expectations. Taken together they constitute the dynamic system that determines the real-time evolution of the economy. Because government bonds and real balances are state variables that affect consumption and output, expectations $y^{e}, \pi^{e}$ are no longer sufficient statistics for the economy and it is now not possible to characterize the dynamics of the system using a phase diagram as in (39) and Figure 2. We therefore directly simulate the real-time dynamics of the system under learning.

To illustrate the possibility of wealth effects successfully leading the economy back to the targeted steady state we provide a numerical simulation. Assume that initial expectations are pessimistic, with $\pi^{e}(0)=0.9425$ and $y^{e}(0)=0.9925$. These expectations are below the low inflation steady state values and therefore in the deflation trap region when households are Ricardian. In the case of non-Ricardian households discussed in Section 2.3 the evolution of output and inflation also depend on wealth dynamics. We are interested in whether these wealth dynamics can lead the economy to the targeted steady state. We find that this indeed is possible, but that there is sensitivity to the tax policy parameters and to the initial wealth of the households.

As an illustration consider the tax function (5) with $\kappa_{0}=0.05$ and $\kappa=$ 
$\beta^{-1}-1+0.001$, so that fiscal policy is passive in the sense of Leeper (1991). ${ }^{11}$ We set $\chi=0.03$ to match the fraction of real balances to consumption (see (30)), and we set the gain parameter $\omega=0.01$. The initial values of real balances and real bonds are $m(0)=0.75$ and $b(0)=0.77$, which are close to the values of $m$ and $b$ at the targeted steady state for this tax function. Figure 3 illustrates the dynamics of inflation and output from this starting point.

Fig30

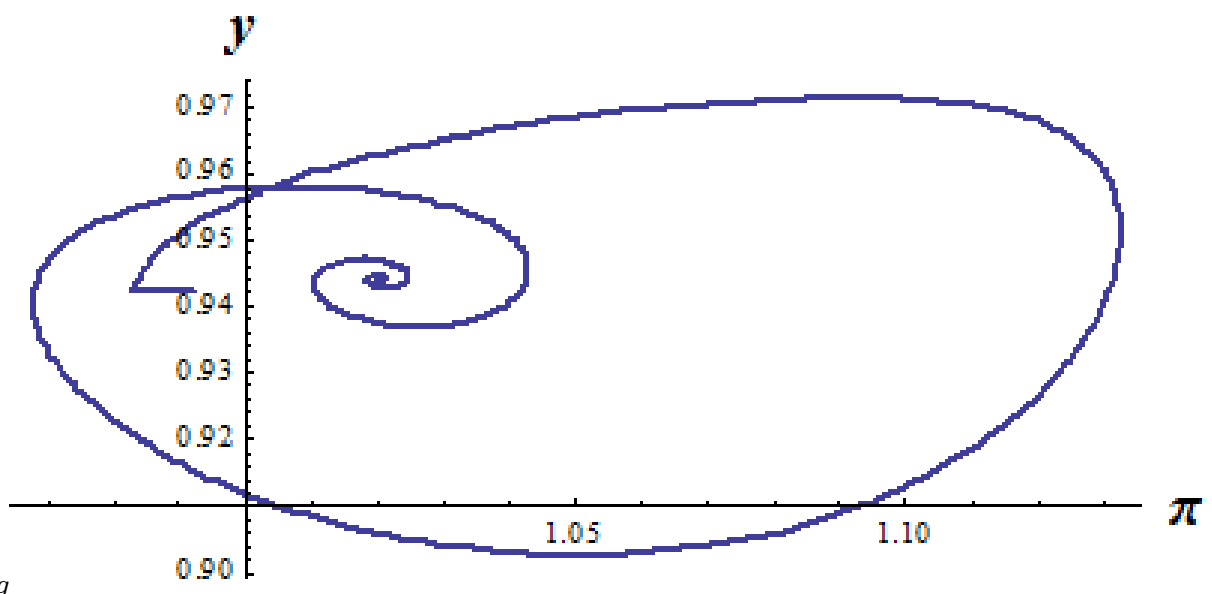

Figure 3: Inflation, output dynamics with non-Ricardian consumers

Figure 3 shows actual inflation and output on horizontal and vertical axes, respectively. There is a wide clockwise cycle where inflation and output at first overshoot $\left(\pi^{*}, y^{*}\right)$, then spiral below $\left(\pi_{L}, y_{L}\right)$ and finally follow a cyclical convergent path to $\left(\pi^{*}, y^{*}\right)$. The time paths of money and bonds eventually also converge to their steady state values. Thus, in this example wealth effects do lead to eventual convergence to the targeted steady state, in contrast to the divergent deflationary path that would arise with Ricardian consumers. However, the path in Figure 3 has an extended period of low output and substantial deflation followed by big swings in inflation and output.

Convergence from pessimistic initial expectations to the targeted steady state appears to be robust with respect to the level of initial wealth (in

\footnotetext{
${ }^{11}$ The other parameters are set at their previous values. The value of $\phi_{y}=50$ corresponds to the output coefficient of linearized Taylor rule of 0.5 at the intended steady state.
} 
particular real bonds) for this value of the tax parameter $\kappa=\beta^{-1}-1+0.001$. We find convergence from various starting values of $m(0)$ and $b(0)$, except for initial bond values $b(0)$ at levels that are very high, for example 20 times that of GDP or higher. This result however is sensitive to the value of $\kappa$. If $\kappa$ is decreased, for example to $\kappa=\beta^{-1}-1-0.001 \approx 0.0091$, then levels of money and bonds eventually explode. The reason is that now fiscal policy is active in the sense of Leeper (1991). At the unintended steady state, monetary policy is passive, and learning dynamics lead the economy towards the intended steady state. However, at the intended steady state, both fiscal and monetary policies are now necessarily active, and financial wealth levels will diverge. We have examined this case numerically for nonRicardian consumers and found that it leads to instability under learning. In simulations the economy appears to move around the targeted steady state for a period but eventually bonds follow an explosive path and the economy diverges. ${ }^{12}$

From a policy perspective, under some circumstances it is possible for wealth effects to provide a mechanism for the economy to escape from a deflationary situation and to return eventually to the targeted steady state. However, this mechanism relies on consumers being non-Ricardian and on appropriate tax policy. Furthermore, the path back to the targeted steady state is cyclical with wide swings in inflation and output.

\section{Fiscal Policy}

We now examine the role of fiscal policy when large adverse expectation shocks make deflation traps and stagnation a serious risk. ${ }^{13}$ We focus on changes in government purchases of goods and services, rather than tax changes with unchanged government spending, because in our set-up, if households are Ricardian, then tax changes by themselves are neutral. In practice, tax changes financed by changes in government debt can have

\footnotetext{
${ }^{12}$ These results are not surprising in view of the (flexible-price, short decision-horizon) results in Evans and Honkapohja (2005). In that paper under steady state learning there is convergence to $\pi^{*}$ but with debt exploding under active fiscal policy. In the current paper with non-Ricardian households the explosive debt path eventually destabilizes inflation and output as well.

${ }^{13}$ Evans and Honkapohja (2010) show that for some points within the deflation trap region, even committing to zero net nominal interest rates forever may be insufficient for escaping the inflation trap.
} 
macroeconomic effects, e.g. if some households are liquidity constrained or are non-Ricardian. ${ }^{14}$ However, our objective is to demonstrate that suitable fiscal rules, based on temporary increases in government spending, can prevent the economy from falling into or becoming stuck in the deflation trap and can return the economy to the targeted steady state, even if tax changes by themselves are neutral. Therefore in this section we focus on Ricardian households. We will briefly return to the non-Ricardian consumers in the next section.

\subsection{Temporary Fiscal Stimulus}

A traditional countercyclical policy for an economy facing deflation with declining or stagnant output is a fiscal stimulus taking the form of increased government expenditures above their normal levels for a finite time horizon, after which they revert to lower levels. We want to study the effectiveness of such a policy under the Ricardian assumption that the government remains solvent in the long run, and that consumers know and expect this. In this IH learning framework agents know the trajectory of government expenditures, including the date at which the expenditures will return to lower levels, and they incorporate this knowledge into their optimal consumption and pricing decisions. Then the consumption function, aggregate demand and the Phillips curve reflect these forward-looking expectations of the agents.

More explicitly, we consider a simple case of anticipated changes in government policy. Suppose that there is an initial pessimistic expectations shock that lowers $\pi^{e}(0)$ and $y^{e}(0)$ sufficiently so that the economy is in the deflation trap region. Under normal policy the economy will fail to return to the targeted steady state. We therefore consider fiscal policies in which there is a temporary increase in $\bar{g}$ (from its initial steady state level $\bar{g}=\bar{g}_{1}$ ), taking the form

$$
g_{t}=\left\{\begin{array}{c}
\bar{g}_{0} \text { for } t=0, \ldots, T_{0} \\
\bar{g}_{1} \text { for } t=T_{0}+1, \ldots
\end{array},\right.
$$

where $\bar{g}_{0}>\bar{g}_{1}$. Here we assume that the policy is announced at $t=0$ and is credible. Thus agents understand that government spending will be continued at the higher level $\bar{g}_{0}$ through period $T_{0}$ and that it will be reduced to its previous level beginning at $T_{0}+1$. We are here studying the economy under

\footnotetext{
${ }^{14}$ There is empirical evidence of positive impacts of tax reductions on aggregate output - see Romer and Romer (2010).
} 
adaptive learning, but with anticipated future policy changes, as discussed in Evans, Honkapohja, and Mitra (2009).

For gross output agents are assumed to have expectations given by the simple adaptive rules described in Section 3. For net output, however, expectations are given by

$$
\text { nety } y_{j}^{e}=\left\{\begin{array}{c}
y_{j}^{e}-\bar{g}_{0} \text { for } j=t, \ldots, T_{0} \\
y_{j}^{e}-\bar{g}_{1} \text { for } j=T_{0}+1, \ldots
\end{array},\right.
$$

so that agents incorporate the known future path of government spending into their forecasts.

The variables nety $y_{j}^{e}$ that appear in the Phillips curve (15), and in the consumption function (37) are now defined according to (40). This requires evaluating the weighted sums of nety $y_{j}^{e}$ using the appropriate value of government expenditures for each $j$. The computations are straightforward, and the consumption function is now given by:

$$
c_{t}=(1-\beta)\left(y_{t}-\bar{g}_{0}+\left(y_{t}^{e}-\bar{g}_{0}\right) \frac{1-\left(r_{t}^{e}\right)^{t-T_{0}}}{\left(r_{t}^{e}\right)-1}+\left(y_{t}^{e}-\bar{g}_{1}\right) \frac{\left(r_{t}^{e}\right)^{t-T_{0}}}{\left(r_{t}^{e}\right)-1}\right)
$$

For the interest rate rule (9) we set $A=2.5$ and $\phi_{y}=50$, a calibration approximately consistent with the standard Taylor-rule parameters.

Fig40

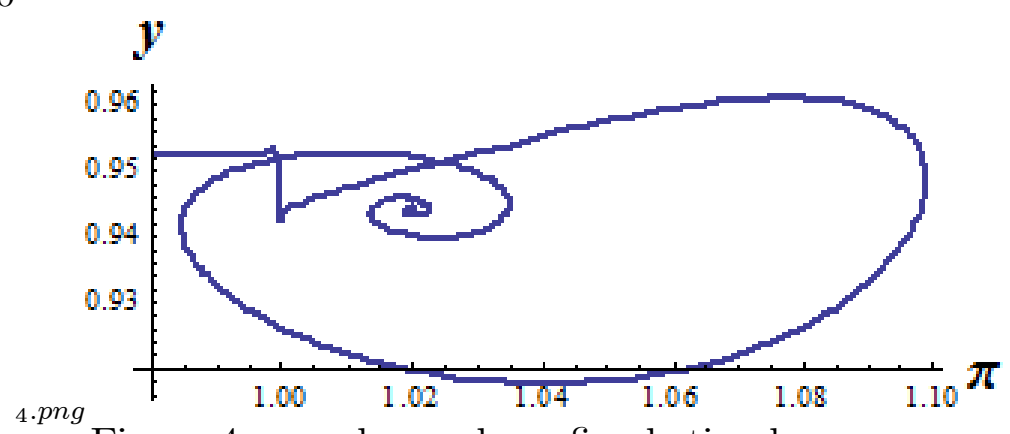

Figure 4: $y$ and $\pi$ under a fiscal stimulus.

Given a specific fiscal stimulus, we can proceed as in Section 3.2, except that we now report real-time dynamics based on the adaptive learning rules of Section 3. Figure 4 illustrates one example of the dynamics of output and inflation for $T_{0}=6$, and with $\bar{g}_{0}=0.21, \bar{g}_{1}=0.2$. Thus there is a fiscal stimulus, taking the form of a $5 \%$ increase in government spending for six 
periods. We set initial expectations at $y^{e}[0]=0.9425$ and $\pi^{e}[0]=0.993$. These are in the deflation trap region, and without the fiscal stimulus there would be falling inflation and output. Under the fiscal stimulus the economy instead converges to the intended steady state, though after a wide swing that takes inflation well above the intended steady state.

An important feature of the policy is that the length of the temporary fiscal stimulus is crucial for its efficacy. For example, if, holding $\bar{g}_{0}=0.21$, $\bar{g}_{1}=0.2$, we set $T_{0}=1,2$ or $T_{0} \geq 37$ then the fiscal stimulus does not enable the economy to return to the targeted steady state. In fact, the size of the stimulus and the degree of pessimism of expectations also matter for the efficacy of fiscal stimulus. We now examine this more systematically. ${ }^{15}$

We consider four different degrees of pessimism of expectations as follows:

Mild: $\pi^{e}=0.993$ and $y^{e}=0.9425$.

Large: $\pi^{e}=0.991$ and $y^{e}=0.9425$

Severe: $\pi^{e}=0.985$ and $y^{e}=0.9425$

Extreme: $\pi^{e}=0.985$ and $y^{e}=0.9$.

We find that a temporary fiscal stimulus always works for a range of government spending $\bar{g}_{0}$ and length of stimulus $T_{0}$. For $T_{0}=1$, a temporary fiscal stimulus works for sufficiently large $\bar{g}_{0}$. Often, increasing length of stimulus $T_{0}$ somewhat allow the use of a smaller value of $\bar{g}_{0}$ to achieve convergence to the intended steady state.

Some specific results are as follows:

Mild pessimism: $\bar{g}_{0}=0.205$ yields desired convergence for stimulus of length $T_{0}=11, \ldots, 22$, while with this $g_{0}$, the policy fails if $T_{0}$ is outside this range. A smaller value of $\bar{g}_{0}=0.204$ is never effective while $\bar{g}_{0}=.25$ makes the $T_{0}$ range larger.

Large pessimism: A large value of spending $\bar{g}_{0}=0.25$ delivers desired convergence for $T_{0}=1, \ldots, 37$. A smaller value $\bar{g}_{0}=0.21$ fails.

Severe pessimism: With $T_{0}=1, \bar{g}_{0}=0.34$ is effective.

Extreme pessimism: With $T_{0}=5, \bar{g}_{0}=0.8$ is effective.

Thus, the fiscal stimulus must be adequate in size and length to push the economy out of the deflation trap region. The intuition for these results is that the demand stimulus from a temporary increase in $g$ outweighs the

\footnotetext{
${ }^{15}$ Also the parameter $T$ describing statistical forecasting horizon affects the quantitative results. Through period $t+T$ agents use their forecasts $\pi^{e}(t)$, whereas after $t+T$, they assume that the real interest rate has reverted to normal and set $r_{t+j}^{e}(t)=\beta^{-1}$ for $j>T$. We set $T=28$ i.e. agents think it will take 7 years for real interest rates to return to normal steady state.
} 
partially offsetting reduced consumption from the higher present value of taxes, which for Ricardian households equals the present value of government spending. A permanent increase in $\bar{g}$ in this set-up does not lift the economy out of the deflation trap, because the permanently higher taxes exactly offset the increase in government spending. In contrast, a large enough increase in government spending for a limited period will add enough stimulus to lead the economy back to the targeted steady state.

\subsection{Fiscal Austerity}

Perhaps surprisingly, it turns out that a carefully designed restrictive fiscal policy can in certain cases lift the economy out of the liquidity trap, provided it is applied for a sufficient long period of time. We now examine this possibility for the different degrees of pessimism of expectations. ${ }^{16}$ The results are as follows:

Mild pessimism: cutting government spending to $\bar{g}_{0}=0.19$ is effective in moving the economy out of the deflation trap when the length of the policy is in the range $T_{0} \geq 33$ but this policy fails for smaller values of $T_{0}$. A more severe policy $\bar{g}_{0}=0.15$ is effective also for $T_{0} \geq 28$.

Large pessimism: $\bar{g}_{0}=0.19$ is effective for length $T_{0} \geq 67$.

Severe pessimism: $\bar{g}_{0}=0.15$ is effective for length $T_{0} \geq 100$.

Extreme pessimism: Fiscal austerity is never effective.

We remark that in terms of the length of policy $T_{0}$, stimulus and austerity policies have an interesting contrast. The efficacy of the former requires a limited duration whereas a very long period of the latter is necessary. In all our examples the efficacy of stimulus policies imply that the austerity policies of same absolute magnitude and duration are not effective and vice versa. However, there are also cases for which neither policy is effective for certain intermediate durations. As an example consider the stimulus policy $\bar{g}_{0}=0.25$ under mild pessimism for a forecasting horizon $T=60$. A stimulus policy with $T_{0} \geq 25$ is ineffective in lifting the economy out of the deflation trap as is an austerity policy of $\bar{g}_{0}=0.15$ for $T_{0}<28$.

In general, we note that efficacy of austerity policies is more sensitive to the degree of pessimism of expectations as suggested by the following subtle intuition. If the economy is in a region in which the ex-ante real interest rate

\footnotetext{
${ }^{16}$ In this section the forecasting horizon is set at $T=60$. For shorter horizons, for example for $T=28$, fiscal austerity seems to be ineffective. On the other hand, temporary fiscal stimuli continue to be effective for large values of $T$.
} 
factor is less than $\beta^{-1}$ then the consumption function dictates an increase in consumption flow stemming from a fixed permanent decrease in taxes, which is larger than the decrease in $g$. The present value is the same when measured by $r^{e}$, but because $r^{e}<\beta^{-1}$, households will substitute toward current consumption. Formally consider a permanent change in government spending to $\bar{g}_{0}<\bar{g}_{1}$. Then actual output, for given expectations, is given by

$$
y_{t}=\bar{g}_{0}+\left(\beta^{-1}-1\right)\left(y_{t}^{e}-\bar{g}_{0}\right) /\left(r_{t}^{e}-1\right)>\bar{g}_{1}+\left(\beta^{-1}-1\right)\left(y_{t}^{e}-\bar{g}_{1}\right) /\left(r_{t}^{e}-1\right),
$$

provided $\beta^{-1}>r_{t}^{e}$. This effect only holds for a range of $\pi^{e}$ in which monetary policy delivers a low $r^{e}$. For larger deflation rates, however, i.e. $\pi^{e}<0.985$, this policy cannot work for initial expectations in which $\pi^{e}(t)$ falls over time under normal policy. Thus for sufficiently pessimistic initial expectations we would expect permanent or very long cuts in government spending to fail as a policy that takes the economy to a steady state.

The above analysis also implies that under adaptive learning, whether households are Ricardian or not, a fiscal stimulus can give rise to a "fiscal multiplier" quite different than a policy of fiscal austerity, depending on the magnitude and duration of the policy and on the initial expectations. This suggests that in an adaptive learning context, results of empirical studies of the fiscal multiplier will be sensitive to initial expectations and to the duration and magnitude of policies.

In this section we have shown that the success of the temporary fiscal policy in general depends on fine tuning the magnitude, direction and duration of the policy. We next look at an endogenous switching rule for government spending that eliminates deflation and stagnation and that also appears to have reasonable performance overall.

\section{$5 \quad$ Fiscal Switching Rules}

To prevent deflationary spirals, or deflation with declining or stagnant output, we now explore government spending policies designed to keep inflation above a certain threshold $\tilde{\pi}>\pi_{L}$. When $\pi^{e}>\tilde{\pi}$ the government sets $g=\bar{g}$. However, if expected inflation drops below $\tilde{\pi}$, and actual inflation would be below expected inflation with $g=\bar{g}$, then the government increases $g$ to achieve an output level $y$ such that realized inflation exceeds expected inflation $\pi_{t}^{e}$. We will call such a fiscal policy rule a fiscal switching rule. 
To implement this fiscal switching policy, we assume that the government monitors expectations. Given expectations, from equation (25), it can set $g$ to achieve a level of $y .{ }^{17}$ From equations (26), (27) and (28) it is apparent that $y$ can be chosen to attain the required level of inflation. This procedure ensures that eventually $\pi^{e} \geq \tilde{\pi}$. We simulate this economy using the same parameters used in Figure 4 above for Ricardian consumers, except that we now use the fiscal switching rule. ${ }^{18}$

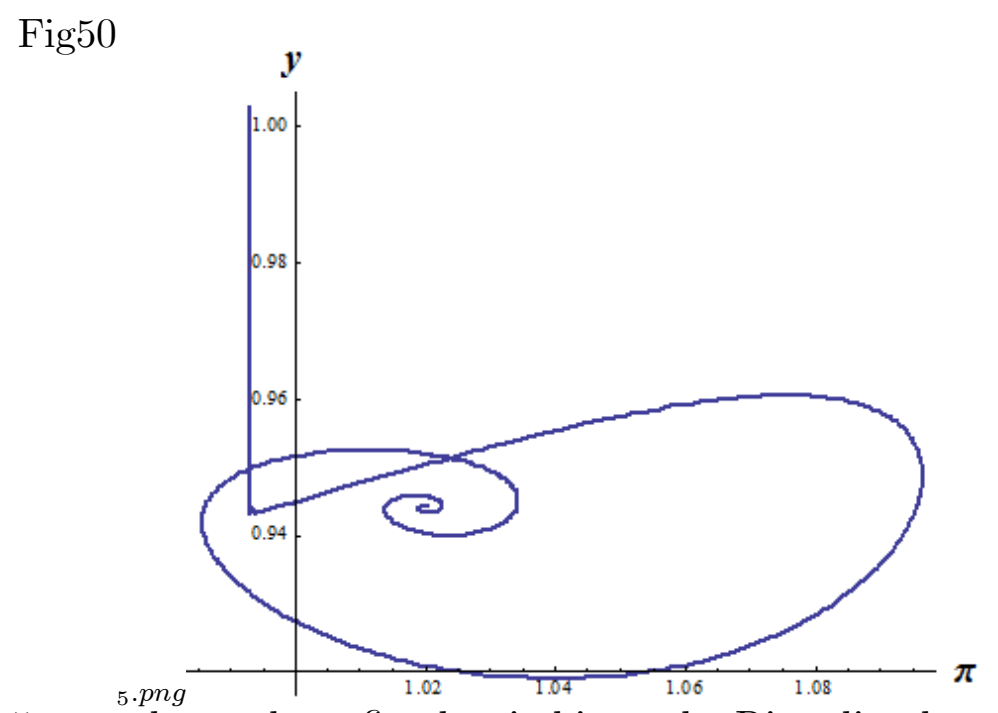

Figure 5: $y$ and $\pi$ under a fiscal switching rule, Ricardian households

Two further points should be noted about this form of fiscal policy. First, it is not necessary to decide in advance the magnitude and duration of the fiscal stimulus. Second, in contrast to the preceding section we now do not assume that agents know the future path of government spending. Instead agents use adaptive learning to forecast the future values of their net income in addition to forecasts of inflation and output.

\footnotetext{
${ }^{17}$ In effect the government observes inflation monthly, and would be able to adjust spending in order to maintain $\tilde{\pi}<\pi$ on a quarterly basis. Aggressive automatic stabilizers may be useful for this purpose.

${ }^{18}$ The results are essentially unchanged if we modify the interest rate rule so that the nominal rate now depends on the net output expectations relative to net output at targeted steady state. An interest rate rule based on net output may appear more appealing because it would insure that monetary policy does not work against the fiscal stimulus when the economy is subject to a deflation trap. However, in our simulations interest rates remain near zero during the initial fiscal stimulus, so using gross rather than net output for the interest rate rule makes little difference.
} 
We start with the case in which consumers are Ricardian. In contrast to the economy depicted in Figure 2, the fiscal switching rule eliminates the unintended steady state with the inflation rate $\pi_{L}$ : the path starting in the vicinity of $\pi_{L}$ converges to the intended steady state. This is illustrated in Figure 5. A strong fiscal stimulus generates a steep rise in output and lifts the economy out of the deflation trap and the economy eventually converges to the intended steady state. For initial expectations in Figure 5, which are the same as in Figure 4, the dynamics would be unstable without the fiscal switching rule.

Fig60

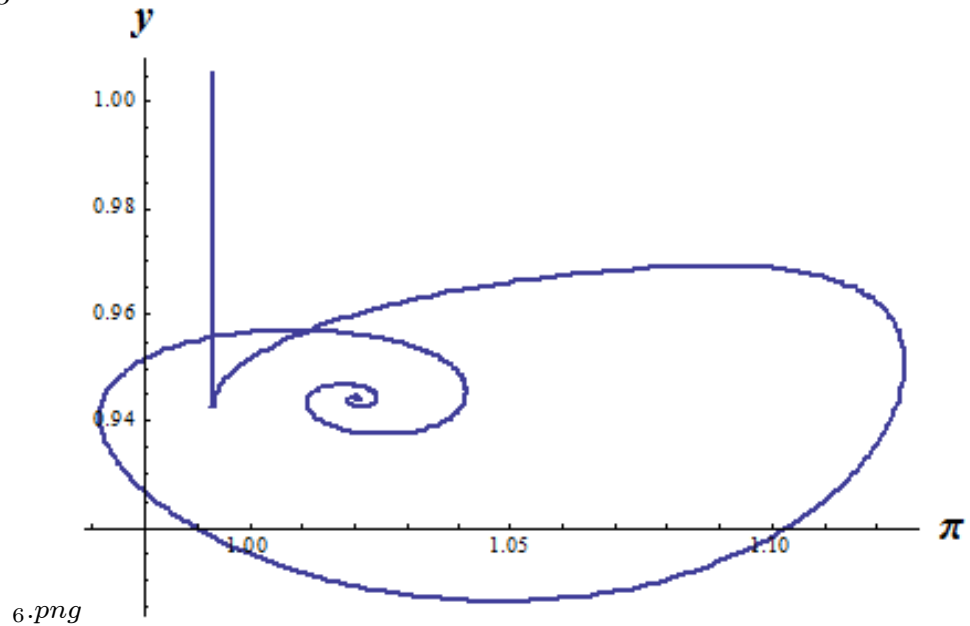

Figure 6: $y$ and $\pi$ dynamics under fiscal switching rule, non-Ricardian households

The results with non-Ricardian consumers are similar: the fiscal switching rule eliminates the unintended steady state $\pi_{L}$. Figure 6 , using the same parameters used for the non-Ricardian case of Figure 3, illustrates these results.

As illustrated in Figures 5 and 6, in both Ricardian and Non-Ricardian cases the fiscal switching rule, together with our interest rate rule, yields convergence to the targeted steady state after an initial overshooting of inflation and output. The overshooting arises from the necessary big initial policy responses that are needed to counteract the initial pessimistic expectations. We also checked that with this combination of rules there is convergence to the targeted steady state from even more pessimistic initial expectations.

In summary, our analysis suggests that one policy that might be used to combat stagnation and deflation, in the face of pessimistic expectations, 
would consist of a fiscal switching rule combined with a Taylor-type rule for monetary policy. The fiscal switching rule applies when inflation expectations falls below a critical value. The rule specifies increased government spending to raise inflation above inflation expectations in order to ensure that inflation is gradually increased until expected inflation exceeds the critical threshold. This part of the policy eliminates the unintended steady state and makes sure that the economy does not get stuck in a regime of deflation and stagnation. Furthermore, unlike the temporary fiscal policies discussed in the previous section, the switching rules do not require fine tuning and are triggered automatically. Remarkably, our simulations indicate that this combination of policies is successful regardless of whether the households are Ricardian or non-Ricardian.

\section{Conclusion}

We have studied how the an economy can fall into a deflation or low inflation trap with declining or stagnant output, and explored the design of policies to avoid such outcomes. Under the perfect foresight view, announced money growth and/or fiscal policies can in principle avoid low inflation. The effectiveness of such policies however depends on the assumption of perfect foresight, on policy credibility, and on wealth effects to eliminate all equilibria except the targeted $\pi^{*}$ steady state. Furthermore such policies are "too powerful" under perfect foresight: bad outcomes never happen.

If we adopt a more plausible adaptive learning view, outcomes with low inflation and output are still possible. We find that policies of temporary fiscal stimulus, and in some cases fiscal austerity, can eliminate liquidity traps and can lead the economy back to its intended steady state. However, such policies require careful fine tuning of the magnitude, direction and duration of the policy. A "fiscal switching rule" that automatically triggers a stimulus of high government expenditures when inflation falls below a critical threshold is

equally effective in stabilizing the economy, but does not require complicated and discretionary fine tuning, and therefore seems preferable. 


\section{Appendix: Asymmetric Price Adjustment}

If the costs of price adjustment are asymmetric and are higher for reductions in prices, then this can provide a lower bound on deflation. ${ }^{19}$ Consider for example the case where the cost of price adjustment in the utility function takes the form

$$
\text { Cost }=\left\{\begin{array}{c}
\frac{\gamma}{2}\left(\pi_{s, t}-1\right)^{2} \text { for } \pi_{s, t} \geq \underline{\pi} \\
+\infty \text { for } \pi_{s, t}<\underline{\pi},
\end{array}\right.
$$

where $\pi_{s, t}=P_{s, t} / P_{s, t-1}$. To examine the implications of asymmetric priceadjustment costs, we return to the case of Ricardian consumers discussed in Section 3.2. The temporary equilibrium map for inflation is modified to

$$
\pi_{t}=\left\{\begin{array}{c}
G_{2}\left(y_{t}, y_{t}^{e}\right) \text { for } G_{2}\left(y_{t}, y_{t}^{e}\right) \geq \underline{\pi} \\
\underline{\pi} \text { for } G_{2}\left(y_{t}, y_{t}^{e}\right)<\underline{\pi} .
\end{array}\right.
$$

Because the Ricardian case is a forward-looking two-dimensional system with adaptive learning, one can illustrate the possible results using phase diagrams showing the expectational learning dynamics. There are three cases:

1. $\underline{\pi}>\pi_{L}$. In this case $\pi^{*}$ is globally stable, since $\pi<\pi_{L}$ is no longer possible.

2. $\underline{\pi}<\pi_{L}$. The deflation trap continues to exist. If $\pi_{L}-\underline{\pi}$ is small, however, in the region $\underline{\pi}<\pi^{e}<\pi_{L}$ there is gradually falling output.

3. $\underline{\pi}=\pi_{L}$. The stagnation regime. In this case there can be convergence to any $0<y<y_{L}$ with $\pi=\pi_{L}$.

Figures 7 illustrates the phase diagram for the E-stability differential equations in $\left(\pi^{e}, y^{e}\right)$-space for the case $\underline{\pi}<\pi_{L}$ in which a deflation trap continues to exist. In this case the targeted steady state $\pi^{*}$ is locally stable and, as can be seen, the basin of attraction can be fairly large. However, if output expectations are low, the economy may converge to the trap even if initially inflation expectations are low but above $\pi_{L}$. The main difference from the symmetric price-adjustment cost set-up examined in the paper is that deflation is now bounded from below at rate $\underline{\pi}$. Thus, in this case, persistently low and falling output is compatible with steady deflation at low levels.

\footnotetext{
${ }^{19}$ See Evans (2012) for the stagnation regime.
} 


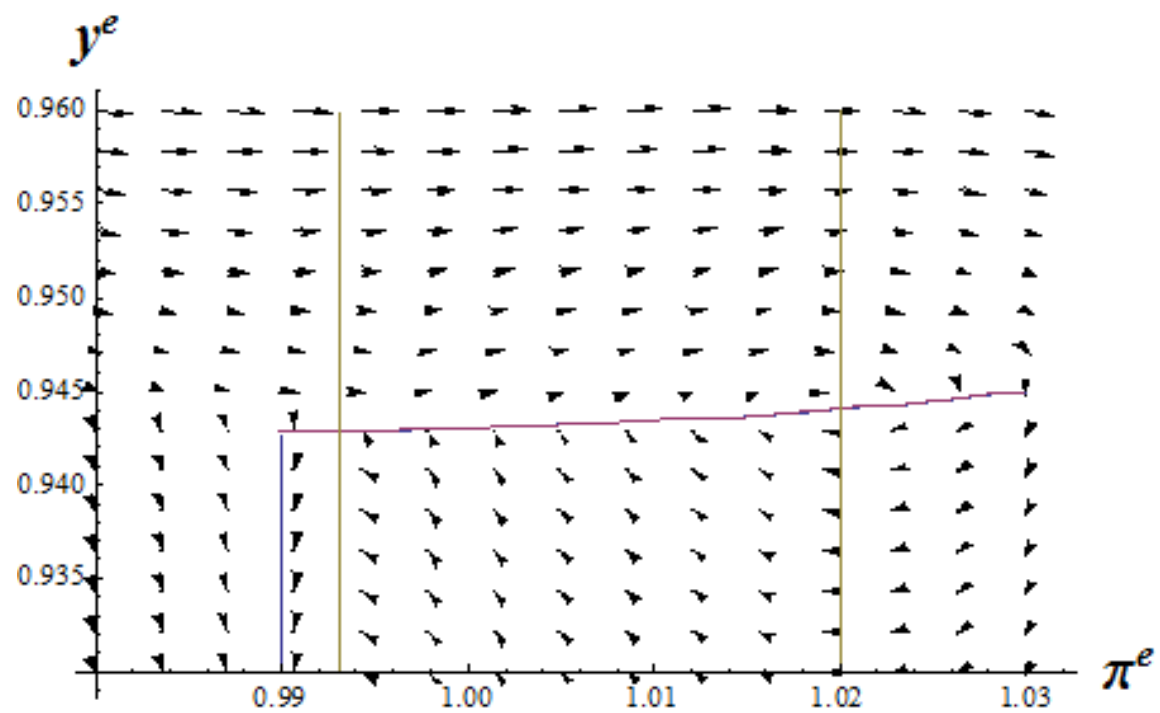

Figure 7: asymmetric cost adjustment with $\underline{\pi}<\pi_{L}$.

We briefly describe the other two cases of asymmetric adjustment costs. In all cases the targeted steady state is locally stable under learning. If $\underline{\pi}=\pi_{L}$, there is also a locally stable continuum of steady states at $\pi=$ $\pi_{L}=\underline{\pi}$ and $y<y_{L}$, where $y_{L}$ is the level of output associated with the usual $\pi_{L}$ steady state. E-stability dynamics indicate that under learning the economy can converge to any point on the continuum from initial conditions $\pi^{e}(0) \gtrsim \underline{\pi}$ and $y^{e}(0)$ sufficiently low. Similar convergence to the continuum can happen for initial $\pi^{e}(0) \lesssim \underline{\pi}$ and $y^{e}(0)$ sufficiently low. In the case $\underline{\pi}>\pi_{L}$ the economy under learning is globally stable at the targeted steady state $\pi^{*}$. However, for $\underline{\pi}$ only slightly above $\pi_{L}$, pessimistic initial expectations $\left(\pi^{e}(0), y^{e}(0)\right)$ can lead to extended periods of low output and mild deflation before inflation expectations are pulled up towards $\underline{\pi}$ and a recovery begins.

As noted, for example, by Bullard (2010), we do observe economies exhibiting extended periods of very low inflation or mild deflation. The cases $\underline{\pi}=\pi_{L}$ and $\underline{\pi}<\pi_{L}$ show that steady mild deflation is consistent with a deflation trap region that leads to persistently falling or persistently low levels of output. The analysis of fiscal policy provided in this paper could easily be extended to the various cases of asymmetric price adjustment. 


\section{References}

Basu, S., And J. G. Fernald (1997): "Returns to Scale in U.S. Production: Estimates and Implications," Journal of Political Economy, 105, 249-283.

Benhabib, J., S. Schmitt-Grohe, and M. Uribe (2001): "The Perils of Taylor Rules," Journal of Economic Theory, 96, 40-69.

(2002): "Avoiding Liquidity Traps," Journal of Political Economy, 110, 535-563.

Bullard, J. (2010): "Seven Faces of The Peril," Federal Reserve Bank of St. Louis Review, 92, 339-352.

Bullard, J., And I.-K. Cho (2005): "Escapist Policy Rules," Journal of Economic Dynamics and Control, 29, 1841-1866.

Cobham, D., Ø. Eitrheim, S. Gerlach, and J. F. Qvigstad (eds.) (2010): Twenty Years of Inflation Targeting: Lessons Learned and Future Prospects. Cambridge University Press, Cambridge.

Eggertsson, G. B., and M. Woodford (2003): "The Zero Bound on Interest Rates and Optimal Monetary Policy," Brookings Papers on Economic Activity, (1), 139-233.

Eusepi, S. (2007): "Learnability and Monetary Policy: A Global Perspective," Journal of Monetary Economics, 54, 1115-1131.

Evans, G. W . (2012): "The Stagnation Regime of the New Keynesian Model and Recent US Policy," in Sargent and Vilmunen (2012), chap. 4.

Evans, G. W., E. Guse, and S. Honkapohja (2008): "Liquidity Traps, Learning and Stagnation," European Economic Review, 52, 1438-1463.

Evans, G. W., And S. Honkapohja (2001): Learning and Expectations in Macroeconomics. Princeton University Press, Princeton, New Jersey.

- (2005): "Policy Interaction, Expectations and the Liquidity Trap," Review of Economic Dynamics, 8, 303-323.

- (2009): "Learning and Macroeconomics," Annual Review of Economics, 1, 421-451. 
(2010): "Expectations, Deflation Traps and Macroeconomic Policy," in Cobham, Eitrheim, Gerlach, and Qvigstad (2010), chap. 12, pp. 232260.

Evans, G. W., S. Honkapohja, and K. Mitra (2009): "Anticipated Fiscal Policy and Learning," Journal of Monetary Economics, 56, 930953.

(2012): "Does Ricardian Equivalence Hold When Expectations are not Rational?," Journal of Money, Credit and Banking, forthcoming.

Krugman, P. R. (1998): "It's Baaack: Japan's Slump and the Return of the Liquidity Trap," Brookings Papers on Economic Activity, (2), 137-205.

Leeper, E. M. (1991): 'Equilibria under 'Active' and 'Passive' Monetary and Fiscal Policies," Journal of Monetary Economics, 27, 129-147.

Leijonhufvud, A. (1973): "Effective Demand Failures," Swedish Journal of Economics, 75, 27-48.

Loayza, N., and R. Soto (eds.) (2002): Inflation Targeting: Design, Performance, Challenges. Central Bank of Chile, Santiago, Chile.

McCallum, B. T. (2002): "Inflation Targeting and the Liquidity Trap," in Loayza and Soto (2002), pp. 395-437.

Patinkin, D. (ed.) (1965): Money, Interest, and Prices. Harper and Row, New York.

Pigou, A. C. (1943): "The Classical Stationary State," Economic Journal, $53,343-351$.

Preston, B. (2005): "Learning about Monetary Policy Rules when LongHorizon Expectations Matter," International Journal of Central Banking, $1,81-126$.

_ (2006): "Adaptive Learning, Forecast-based Instrument Rules and Monetary Policy," Journal of Monetary Economics, 53, 507-535.

Reinhart, C. M., and K. S. Rogoff (2009): "The Aftermath of Financial Crises," American Economic Review, Papers and Proceedings, 99, 466-472. 
Romer, C. D., and D. H. Romer (2010): "The Macroeconomic Effects of Tax Changes: Estimates Based on a New Measure of Fiscal Shocks," American Economic Review, 100, 763-801.

Rotemberg, J. J. (1982): "Sticky Prices in the United States," Journal of Political Economy, 90, 1187-1211.

Sargent, T. J. (1993): Bounded Rationality in Macroeconomics. Oxford University Press, Oxford.

(2008): "Evolution and Intelligent Design," American Economic Review, 98, 5-37.

Sargent, T. J., and J. Vilmunen (eds.) (2012): Macroeconomics at the Service of Public Policy. Oxford University Press, forthcoming.

Sbordone, A. (2002): "Prices and Unit Labor Costs: A New Test of Price Stickiness," Journal of Monetary Economics, 49, 265-292.

Svensson, L. E. (2003): "Escaping from A Liquidity Trap and Deflation: The Foolproof Way and Others," Journal of Economic Perspectives, 17, $145-166$. 